\title{
Supporting teachers in data-informed educational design
}

Citation for published version (APA):

McKenney, S., \& Mor, Y. (2015). Supporting teachers in data-informed educational design. British Journal of Educational Technology, 46(2), 265-279. https://doi.org/10.1111/bjet.12262

DOI:

10.1111/bjet.12262

Document status and date:

Published: 18/03/2015

Document Version:

Peer reviewed version

Document license:

CC BY-SA

Please check the document version of this publication:

- A submitted manuscript is the version of the article upon submission and before peer-review. There can be important differences between the submitted version and the official published version of record. People interested in the research are advised to contact the author for the final version of the publication, or visit the DOI to the publisher's website.

- The final author version and the galley proof are versions of the publication after peer review.

- The final published version features the final layout of the paper including the volume, issue and page numbers.

Link to publication

\section{General rights}

Copyright and moral rights for the publications made accessible in the public portal are retained by the authors and/or other copyright owners and it is a condition of accessing publications that users recognise and abide by the legal requirements associated with these rights.

- Users may download and print one copy of any publication from the public portal for the purpose of private study or research.

- You may not further distribute the material or use it for any profit-making activity or commercial gain

- You may freely distribute the URL identifying the publication in the public portal.

If the publication is distributed under the terms of Article 25fa of the Dutch Copyright Act, indicated by the "Taverne" license above, please follow below link for the End User Agreement:

https://www.ou.nl/taverne-agreement

Take down policy

If you believe that this document breaches copyright please contact us at:

pure-support@ou.nl

providing details and we will investigate your claim.

Downloaded from https://research.ou.nl/ on date: 26 Apr. 2023 


\title{
Supporting teachers in data-informed educational design
}

\author{
Susan McKenney ${ }^{1,2}$ \& Yishay Mor
}

${ }^{1}$ Department of Instructional Technology, University of Twente, Enschede, the Netherlands

${ }^{2}$ Center for Learning Sciences and Technologies, Open University of the Netherlands, Heerlen, the

Netherlands

Recent years have seen a growing recognition of the value of positioning teaching as a design science. In this context, we see a great potential in the possible synergy between educational design, learning analytics, and teacher inquiry. This synergy is demonstrated in the form of CASCADE-SEA, a computer-based support tool that assists teachers in creating exemplary lesson materials for secondary level science and mathematics in southern Africa. The purpose of the present study is to articulate how teachers might be supported in the synergistic processes that are integral to educational design. It does so by revisiting existing data collected during the design, development and evaluation of CASCADE-SEA, and sharing the results of a retrospective analysis in light of recent developments in learning analytics, learning design and teacher inquiry. The retrospective analysis revealed insights related to each of the aforementioned themes. For learning analytics, those were: social structures of learning and teaching practices; pedagogy-driven collection and analysis of data; and the use of data to inform teaching and learning. For learning design, the findings pertained to the language, practices and tools used to achieve particular educational aims. For teacher inquiry, the findings relate to the empirical process of question formulation, methods selection, collection and analysis of data, and sharing/reflecting on the findings as well as overall process. Based on the retrospective analysis, design considerations are offered for a modern application to replace the practical and effective desktop software that was developed during the 1990s.

Keywords: Electronic performance support systems, learning analytics, learning design, teacher inquiry

\begin{abstract}
Introduction
Teachers habitually confront complex challenges with limited resources (Mor, Hernández-Leo \& Craft, 2013). In modest, intuitive ways that often capitalize on tacit knowledge, they address challenges through the processes of learning analytics, learning design and inquiry. Learning Analytics is defined as "the measurement, collection, analysis and reporting of data about learners and their contexts" (Ferguson, 2012). Teachers engage in learning analytics when they analyse learner data for the purpose of informing, refining and/or customizing teaching and learning. Often, they use analysis results when engaging in the learning design. Learning Design (LD) is the act of devising new practices, plans of activity, resources and tools aimed at achieving particular educational aims in a given situation (Mor \& Craft, 2012); it results in learning design products (e.g. plans and resources) often referred to as "learning designs". To investigate how learner needs are being met, teachers frequently conduct inquiry, through structured observation or assessment. However, these intuitive and tacit practices of learning analytics, learning design and teacher inquiry are far from the structured and technology-enhanced vision of these three domains common in the academic literature.
\end{abstract}

The integrated model of "teacher-led design inquiry of learning" (Emin-Martínez et al., 2014) illustrates how the three processes of learning analytics, learning design and teacher inquiry could be connected. This model includes the following phases: initiation of a teaching innovation / inquiry; context analysis or investigation; formulation of the design objective and the research question; design artefacts (activity plans, resources, tools) to achieve learning objective and answer design questions (research methods); enactment; evaluation; reflection; and re-design. To lend this process rigour and validity, teachers need access to data at various phases: in the context analysis they need data to illuminate the base conditions in which their inquiry is situated. This data will play a role in formulating the design objective and the research question (in terms of desired change in the observed data). Designing the research method will refer to the available data sources, and possibly define new sources. Finally, the evaluation will rely of data collected in the course of and after enactment. In a 
similar vein, this contribution explores synergistic connections between learning analytics, learning design and teacher inquiry.

Every several years, we are confronted with vocal calls to make education more "scientific" and "evidence-based" (e.g. Davies, 1999; Slavin, 2002). These calls often encounter strong criticism from the educational research community - on methodological as well as ethical grounds. But more importantly, they consistently fail to impact educational practice (Korthagen et al., 2001); teachers find it difficult to access academic research, and when they succeed - they often do not find it relevant to their practice. As an alternative, we propose a model where teachers are themselves engaged in a quasi-scientific process. Such a model builds on the tradition of inquiry-based learning in science education. Indeed, if we want teachers to adopt a scientific approach, then why not use a methodology which has proven itself in teaching science? This idea is not new: when Schön (1992) discusses Dewey's ideas of inquiry, he refers to teachers' practices as much as students'. Recent studies have explored the potential of promoting a culture of inquiry in educational practice (Avramides et al, in press). Others have also made the link between teacher inquiry and learning design, by applying a learning-by-design methodology to teacher training (Makri et al, 2014) or by inducting teachers as design researchers (Sagy \& Kali, 2014; Bannan, 2008). Yet none of these has been operationalised systematically, neither in terms of the tools used for data collection and analysis, nor in the mechanisms of using these data to enhance teaching practice.

Given the aforementioned concerns, the aim of this paper is to contribute to the fields of learning analytics, learning design and teacher inquiry not in isolation, but by articulating how integrated support might be provided to teachers engaging in these complex processes. We study the past in order to inform the future. Specifically, this paper examines what can be learned about integrated support from existing research on CASCADE-SEA. CASCADE-SEA is a computer-based support tool developed to assist teachers in creating exemplary lesson materials that integrates foundational elements of learning analytics, learning design and teacher inquiry. We begin with a discussion of the key concepts of learning analytics, learning design and teacher inquiry. We then focus on a retrospective analysis of the CASCADE-SEA system, in which original data were re-coded using key concepts related to learning analytics, learning design and teacher inquiry. The result is a discussion of design considerations for a modern application to replace the practical and effective desktop software that was developed during the 1990s.

\section{Connected: Learning analytics, learning design and teacher inquiry}

Ferguson (2012) notes the common definition of learning analytics as "the measurement, collection, analysis and reporting of data about learners and their contexts, for purposes of understanding and optimising learning and the environments in which it occurs". Learning analytics typically focuses on online learning environments, leveraging the large volumes of data that they generate to provide learners and teachers with near real-time feedback on their performance and help them optimise the conditions for learning. This process is primarily diagnostic. While learning analytics has gained popularity especially through its focus on big data (e.g. leveraging the abundance of data in virtual and/or massive learning environments), the basic approach is also central to formative assessment at the classroom level - a process that has been shown to substantially impact the quality of teaching and learning in a positive way (Black \& Wiliam, 1998).

Learning design, as a field of practice and research, aims to make the processes and products of designing for learning visible and shareable, open them up for scrutiny, and enhance their quality by incorporating robust pedagogical, technological and organizational principles. For example, Voogt et al (2011) show how engaging teachers in structured learning design enhances their professional expertise and in particular their pedagogical knowledge. Kali, Goodyear and Markauskaite (2011) highlight the value of studying teachers' design practices, and demonstrate this by showing how it exposes teachers' "pedagogical knowledge in pieces", a fragmented and ad-hoc collection of pedagogical ideas, which guide teachers in their design practice - rather than a coherent and consistent pedagogical framework. 
Avramides et al (in press) define Teacher inquiry as a process in which "teachers identify questions for inquiry in their practice and then design a process for collecting evidence about student learning that informs their subsequent learning designs". Teacher inquiry could potentially utilise the outcomes of learning analytics, and at the same time open up new pathways to obtaining data for learning analytics. Schön (1992) identifies Dewey's notion of inquiry as a systematic, rigorous and critical path from doubt to its resolution. Anastopoulou et al (2012) observe several phases in the process of personal inquiry: formulating a question, identifying appropriate methods, collecting and analyzing data, sharing findings and reflecting on the process as a whole. These orientations are helpful in understanding the process of teacher inquiry, which may be open-ended (e.g. "How will my learners react to these new activities?") or shaped to test conjectures (e.g. "Does the newly-designed activities yield the effects I expected?").

Learning analytics, learning design and teacher inquiry stand to be both valuable on their own and mutually enhancing when combined. Persico \& Pozzi (in press) offer a detailed discussion of the possible synergies between them. The conceptual model shown in Figure 1 illustrates that each process is guided by, and can contribute to refinement of, the same rationale. A rationale is a consistent and explicit understanding of: teaching and learning aims; the social, political and physical context; pedagogical vision; and educational values. In addition to building on and contributing to the same rationale, synergies between the three core processes are also present. Specifically, learning analytics of data, teaching/learning practices and social structures can yield understanding that guides learning design. The learning design process yields languages, practices and tools that support teaching and learning enactment. The teacher inquiry process yields insights concerning the enacted learning designs, which can be used to make improvements. Alone or combined, each of these processes is complex. Each presents several challenges to teachers, and requires both time and expertise to do well.

Please insert Figure 1 about here

While many teachers welcome the processes of learning analytics, learning design and inquiry, few have sufficient resources to engage with each in a sustained and systematic manner. Professional communities are a powerful resource (Pareja-Roblin, Ormel, McKenney, Voogt \& Pieters, in press). As are electronic performance support systems (EPSSs) (McKenney, Nieveen \& Strijker, 2008). The context of educational EPSS development has changed dramatically in the last five years, with the arrival of mobile technologies. With the ultimate goal of supporting the design of an EPSS that capitalizes on the affordances of modern technologies as well as insights related to learning design, teacher inquiry and learning analytics, the present study sought to identify characteristics of a valid and practical tool that could synergistically support teachers in the processes of learning analytics, learning design and inquiry. The characteristics were identified through a retrospective analysis of data collected during the CASCADE-SEA study.

\section{The CASCADE-SEA case}

Having identified the potential for enhancing teachers professional practice by providing them with tools and methodologies which combine learning design, learning analytics and teacher inquiry, we wish to proceed towards a specification of a software system which would support such an approach. Rather than working down from abstract constructs, we prefer to base our specifications on a retrospective analysis of a system which has been successfully tested in demanding conditions, thus grounding our observations in realistic strata. The CASCADE-SEA system is deemed appropriate for the purposes of this retrospective analysis because (a) it synergistically combines foundational elements of learning analytics, learning design and teacher inquiry into one system; and (b) evaluation results (McKenney, 2005, 2008) indicate that the software could be deemed valid and practical, with the potential to impact curriculum development (users generally produce better materials than they otherwise would without the system) and teacher professional development (users learn from the process). Initial design requirements for new software were derived by re-coding data from the CASCADE-SEA investigation. 
CASCADE-SEA stands for Computer Supported Curriculum Analysis, Design and Evaluation for Science Education in Africa. It is a software program that helps teacher-designers make use of existing and new data and resources while developing print-based lesson materials. The software was developed to support two mutually enhancing processes simultaneously: curriculum development and teacher professional development. As Jonassen and Reeves (1996, p. 695) put it, “...the people who seem to learn the most from the systematic design of instructional materials are the designers themselves." The design and development of CASCADE-SEA has been described extensively (McKenney, 2001; McKenney, Nieveen \& van den Akker, 2002; McKenney \& van den Akker, 2005; McKenney \& Reeves, 2013). Further, the effectiveness of CASCADE-SEA and its characteristics as an electronic performance support system have also been researched and reported (McKenney, 2005, 2008).

CASCADE-SEA was designed to reside on computers at Teacher Resource Centers (TRCs) throughout southern Africa. Widely accepted across southern Africa as an essential ingredient of a professional support structure for teachers and schools (Hoppers, 1998; Unwin, 2005), TRCs often provide contexts for collaboration with local teachers to develop lesson materials that exemplify specific elements of an innovative curriculum. The process of collaboratively designing materials is invigorating and challenging. It requires analysing context, needs and wishes; developing materials that address core goals while also supporting teachers in enacting appropriate and effective learning activities; and evaluating and fine-tuning the final products.

The CASCADE-SEA program aims to support those groups and individuals involved in the process of creating exemplary lesson materials or teacher guides, usually to be shared among colleagues in the same region. In total, 510 respondents (users and experts) participated in the testing of the CASCADE-SEA system. Six user groups were pre-service teachers, 13 user groups were in-service teachers, and 13 other user groups were curriculum developers. Expert appraisal was conducted with three groups, representing expertise in the areas of science education, curriculum development and teacher professional development. The research and development activities were determined through collaborative deliberation between the researchers and participating organizations. Such collaboration was considered to be the most effective way of assuring that the research setting remain authentic as well as relevant and beneficial to the respondents involved. For example, the CASCADE-SEA software was incorporated in a Zimbabwean science teacher professional development program that already used a 'teacher learning by lesson design' approach. While other respondent groups were exposed to the software only once, this group choose to use the software early, and volunteered to continue using revised versions of the software because its goals were closely aligned with their own.

The main menu screen, presented in Figure 2, shows both the procedural and conceptual model for curriculum development that is supported within this program. CASCADE-SEA is a rich tool, including approximately 250 different activity screens. Here we focus on the most significant elements within the system. Although the model (representation and nomenclature) is unique, it is based on a synthesis of accepted design models (McKenney, 2001). This model is cyclic (emphasizing an iterative approach) and organic (explicitly featuring the core ideas driving the innovation). As this model depicts, four main phases of curriculum development are discerned: rationale, analysis, design and evaluation. The rationale contains the main aims and ideas behind the (to be developed) curriculum, including their implications with regard to the target setting. Located at the hub of the process (Figure 1), the rationale phase influences all others. The process of defining a rationale is likely to raise additional questions. Often the best way to address such questions is to conduct a needs and/or context analysis. This phase contains elements related to learning analytics. An elaborated rationale provides the curriculum developers with guidelines during the (learning) design phase. It also serves as criteria against which inquiry -in this case (formative) evaluation - takes place. In addition to the four main components, the software also features: help, tutorials, an interactive agent and a toolbox containing additional resources. Across the whole program, performance support is offered in four ways: advice (tailor made or generic); tools (internal or external); learning opportunities (procedural or conceptual); communication aids (verbal or written). Figure 3 shows samples of each in CASCADE-SEA, and detailed discussion of support may be found in McKenney (2008). 
Please insert Figure 2 about here

Please insert Figure 3 about here

\section{Methods}

Research question and data sources

The question guiding the retrospective analysis was: Based on existing empirical evidence, what are the characteristics of a valid and practical electronic tool that could synergistically support teachers in the processes of learning analytics, learning design and inquiry? No new data were collected to answer the research question. Rather, existing data from the CASCADE-SEA study were used. The existing data set was accumulated over a period of 4 years, collected through six types of instruments: interview and walk-through schemes; questionnaires; discussion guides; observation and demonstration schemes; logbooks; and document analysis checklists. The instruments were used across 34 distinct circuits of investigation relating to analysis ( 7 circuits), design ( 23 circuits, about 6 for each prototype) or evaluation (4 circuits) of the software.

For example, the $14^{\text {th }}$ circuit took place during the design phase of the study, in cooperation with a science and mathematics educational improvement project. The second prototype of the software was tested out during a week-long writer's workshop sponsored by the project. At this workshop, teachers from all over the country came to this workshop with the goal of creating lesson materials that could be photocopied and shared nationwide. A demonstration of the CASCADE-SEA program was given to all the teachers $(n=34)$ and everyone was encouraged but not required to try it out during the week. Three workstations were set up in the workshop rooms, and assistance was available at all times. Teachers, in small groups and individually, took time to become acquainted with the tool. Comments and feedback were captured through a questionnaire distributed at the end of the workshop. Additionally, data were collected through discussions with project staff and participants were observed using the program. Finally the teacher guides created with CASCADE-SEA were analyzed and compared to those made without aid of the program. Further details on data collection are available (McKenney, 2001; McKenney 2005; McKenney, 2008; McKenney \& van den Akker, 2005).

\section{Data analysis}

For the present study, summarized data from the original set were re-visited in light of recent developments in the fields of learning analytics, learning design and teacher inquiry, as presented above. The existing data were re-coded for relevance to each theme, specifically:

- Learning analytics: social structures of learning and teaching practices; pedagogy-driven collection and analysis of data; and the use of data to inform teaching and learning;

- Learning design: the language, practices and tools used to achieve particular educational aims;

- Teacher inquiry: the empirical process of question formulation, methods selection, collection and analysis of data, and sharing/reflecting on both findings and process.

The results of this retrospective analysis, presented in the following section, provide design requirements for new software.

\section{Results of the retrospective analysis \\ Learning analytics}

The CASCADE SEA case was far from a typical learning analytics context. Nevertheless, it offers an opportunity to consider the potential of extending learning analytics to the (yet more common) faceto-face educational context. Two areas of the software related to the field of learning analytics:

Rationale and Analysis. In the Rationale, users explicate their reasons for making materials, and what kinds of materials would be useful for that particular setting. They are stimulated to activate existing knowledge (or knowledge gaps requiring data collection) concerning the context with questions like, "Does the target group hold a diploma for the subject being taught?" and "What kinds of resources are available in the target schools?" Users can select multiple choice answers to these questions, and also indicate if they are unsure about the answers. For any areas warranting further investigation, The Analysis section helps users investigate the needs and context in which the materials will be used. 
Questions left unanswered (or marked unsure) are brought to this area of the program, and users are supported in conducting empirical investigation to inform themselves about the target group and context in which the materials will be used. This includes helping to formulate key questions, decide on basic investigation strategies, select appropriate methods, develop instruments, collect and analyse data, and report on the findings. It also reminds the user to revisit and update the rationale based on new insights. From the learning analytics perspective, the following themes were explored in the retrospective analysis: Analysis of social structures and learning and teaching practices; pedagogydriven collection and analysis of data; and the use of data to inform teaching and learning.

Pertaining to social structures and learning and teaching practices, respondents asked that the program explicitly try to support cooperation and planning in groups. That is, while the software could be used by individuals, it should be attuned to the fact that teachers are working with others, and support that cooperative work. Respondents indicated that the availability of the software prompted increased collaboration among teachers.

In terms of pedagogy-driven collection and analysis of data, experts suggested that instruments offered in the analysis component could do better in terms of encouraging the user to think, particularly by adding more 'why' questions and not just asking 'what' questions. Respondents wondered: Could the system itself point out gaps between desired and existing situations? Another form of support is helping the user understand consequences of actions taken in the analysis phase. However, because they are so detailed, elements in the analysis component might appear intimidating, and thereby contradict the (rapid) prototyping approach which is advocated through the software. Users (especially teachers involved in classroom research) wanted more tools and guidelines for reporting. Finally, analysis instruments were (generally speaking) longer than necessary... shortened or additional emphasis should be placed on where, why and how users can prune them.

When it came to the use of data to inform teaching and learning, clear explanations were needed about understanding analysis - that priorities (in the design guidelines area) should be based on gaps between the three types of results (from exploring stakeholder perceptions, portraying classroom realities, and synthesizing policy documents). Users wanted the analysis component to not only emphasize observations of the current situation, but also for idea generating: addressing good quality interventions/innovations with regard to the materials to be developed. Cascade was deemed a useful learning tool in many ways, including learning on how data can serve curriculum development. But they also mentioned that the learning would only be sustained if the system were used regularly.

\section{Learning design}

The Design and Toolbox areas of CASCADE-SEA support learning design activities. In the Design area, teachers are supported in choosing topics, setting goals for each module and developing individual lesson plans using self-made and/or ready-made activities from a database. The system supports the work and by offering structure and sample content. The Toolbox offers tools to help the user customize and elaborate the lesson plans and modules using text, graphics, concept mapping and the database of reference designs and resources. Based on Mor, Hernández-Leo \& Craft's (2013) definition of learning design, the retrospective analysis pertaining to learning design focused on the language, practices and tools used to achieve particular educational aims.

The retrospective analysis examined findings related to the language and forms used for representing and sharing designs. The database of reference designs and resources was highly appreciated by teachers. Their only difficulty was with the level of English, a second language for most. This was addressed by adding an interactive agent that provided context-sensitive definitions of key words.

Also examined were the processes by which teachers move from an understanding of the learning context, through identification of educational challenges within it, and on to the generation and testing of solutions addressing these challenges. Using CASCADE-SEA prompted teachers to think about and discuss their own teaching practices; many users said this was the first time they had a chance to reflect on their own educational philosophy and values. Users commented that the software prompted them to approach materials development in a (more) systematic and thorough fashion. Teachers 
expressed willingness to contribute their own lesson plans and activity ideas to the system, and also wanted to be able to comment on existing ones, for the benefit of subsequent users. They appreciated the ease with which users could save (and later access) plans made by themselves or others; they liked the fact that existing materials could be shared, polished or improved upon.

The CASCADE-SEA tool supports the above practices and the discourse around them in multiple ways. Users especially liked the checklist, design guidelines and instruments (especially observation) that were built into the system. Teachers recommended including additional subject-matter support, such as adding more sub- topics; reminding the materials designer to connect to learners' prior knowledge; and adding a section for teacher notes, making inclusion of vocabulary words easy (these were all incorporated into the final system). They also recommended encouraging the CASCADE-SEA user to consider (on behalf of the learners) higher reasoning skills and local applications/relevance of subject matter learning. Teachers overwhelmingly appreciated the flexibility of the system, but also noted that, "like any model, its basic assumption could limit teacher creativity." Users appreciated the basic model and wanted to see strong links between rationale and design. "This package really makes you sit down and think about what you're going to teach, how you're going to teach, how much time is spent on certain activities, what materials are necessary, how it can be that improved, etc. ...A moderator of a [teacher resource centre] can indeed use this program for teacher training and development". Even through the CASCADE-SEA system was designed to be "pedagogically agnostic" (not purveying a specific view of teaching and learning, or privileging one approach over another), concerns were still voiced about alignment between system values and user values.

\section{Teacher inquiry}

Once initial materials (or plans for them) are drafted, the Evaluation area of the program helps users plan, execute and reflect on the findings of formative evaluation to refine the drafted materials essentially, a process of teacher inquiry. In this component, information about draft materials (or global ideas) is collected, analysed and interpreted in a systematic manner, with the goal of determining how these items may be improved. There are seven main elements in the evaluation component (questions, strategies, methods, plan, instruments, respondents, revisions). It bears a significant resemblance to the structure of the analysis component, since both of these phases feature research activities. The fundamental difference between these two components is the nature of questions asked, which influences the strategies used to support them and the kinds of recommendations that are given.

In contrast to the other areas of the program, the Evaluation component was based on prior work (Nieveen, 1997). Also, while intuitive inquiry processes are natural for many teachers, explicit, structured ones are not. These two factors may explain why participants offered limited critique on the structure of the evaluation area. They did comment that CASCADE offers step-by-step guidance through the process of planning an evaluation. They valued the clarity and conciseness of both the procedure to be followed and the instructions on how to do so; and they encouraged more of the same. They found it easy to get around the program and characterized the interface as user-friendly. The majority stated that CASCADE is aligned with the their existing practices of formative evaluation. Participants were satisfied with the content of Evaluation area, and felt that it contained sufficient support.

\section{Discussion}

Reflections on the findings

Based on existing empirical evidence this study sought to identify characteristics of a valid and practical electronic tool that could synergistically support teachers in the processes of learning analytics, learning design and inquiry. CASCADE-SEA users valued various aspects of the program. Although the step-by-step guidance, was among the most highly-appreciated features, it was also a source of tension, because it provided more structure than users were used to. In fact, frequent discussion issues were: whether too much guidance could cause users to "become lazy"; whether the system offered too much freedom, and if a more linear structure would be clearer. The balance between free and structured use is not uncommon in EPSS discussions (McKenney, 2001). Users indicated that the program saved them time and they valued the content support. Linkage to external 
programs was viewed as very positive, as was the system's approach of drafting documents that users could then edit. Another recurring discussion topic pertained to the depth of support the program should offer. Participants could not reach consensus as to where to 'draw the line' between a 'complete' and a 'lite' version of the program.

Mor, Craft, \& Hernández-Leo (2013) note Latour's 'advantages' of design as humility, attentiveness to detail, semiotic skills, remedial intent and an ethical dimension. Humility refers to designer acknowledgement of limitations and being sensitive to the constraints imposed by the context. An example of this in the CASCADE-SEA design is that it prompts users to consider the intellectual, cultural and physical infrastructure of the context for which teachers are designing, and to attune materials accordingly. Operating at different levels of granularity, and ensuring that the critical hazards are addressed represents attentiveness to detail. In the CASCADE-SEA example, users are stimulated to consider many details ranging from educational vision to the visual form and style of the printed materials. Semiotic skills are employed when new artefacts introduced by the designer are woven into a fabric of existing resources. In CASCADE-SEA, attention is especially given to this aspect by supporting users in identifying the content areas of existing subject content and textbooks for which new materials are being created, and clarifying this connection to the end users of the materials. Designs aiming to improve existing situations exhibit remedial intent. Because textbooks are commonly written for pupils in mind, with limited support for teacher implementation, the CASCADE users are prompted to explicate the anticipated added-value their materials will have over the existing situation. Finally, an ethical dimension, whereby the aim to improve embodies an implicit value position of what is 'better', is also present in the CASCADE-SEA work. The program leaves users free to articulate what the improved situation will entail, but suggests it is likely to relate to (a combination of): increased subject-matter knowledge, more learner centred teaching and/or improved classroom management.

\section{Toward design principles for modern tools}

The retrospective analysis of CASCADE-SEA was conducted to identify evidence-based characteristics of a valid and practical electronic tool that could synergistically support teachers in the processes of learning analytics, learning design and inquiry. In light of the observations above, and technological progress, several principles can be articulated. First, synergies between the three processes are revisited, which yields a basic design tenet. Then, in light of CASCADE-SEA and existing literature on this class of tools, key questions are identified for further articulating characteristics of a modern tool. Finally, drawing on the findings of the retrospective analysis, design guidelines are given in relation to learning analytics, learning design and inquiry.

Potential synergies between learning analytics, learning design and teacher inquiry were identified long before these processes had their modern names. Learners' experiences are rooted in a complex web of resources and interactions - many of which are beyond the educators control or even knowledge. This is where Donald Schon's notion of design as "reflective conversation with the materials of a situation" (1992, p. 5) is a powerful idea. Educators create, assemble and arrange resources and activities that they predict will engender certain experiences that will foster growth. They cannot know for certain what would be the resulting experiences or their effects until the learners actually interact with the situations they have created. This is Schon's 'conversation': we create situations and they 'talk back' to us. But as Schon notes, this is not just a process of design, in the creative sense, it is also a process of inquiry. Thus, we see that learning design and teacher inquiry are inherently intertwined. The emerging field of learning analytics promises to use the power of digital technology to track and visualise learners' behaviours, and offer guidance that will make learning more effective. This would appear to offer an unprecedented potential in supporting teacher inquiry into student learning practices. Meeting this potential hinges on a fundamental design tenet: These tools must be based on a deep understanding of learning through experience, and their use must be embedded in meaningful experiences.

McKenney, Nieveen \& Strijker (2008) reviewed information technology tools related to curriculum development, and distinguished three types: knowledge management systems, repositories for reuse, and the type of tools described in this article - electronic performance support systems. Nieveen and 
Gustafson (1999) specifically examined tools that were created with the goals of supporting the curriculum designer in mind, by: improving task performance, increasing transfer of knowledge, and/or yielding organizational learning. They developed a typology to characterize such tools, describing variations in: type of output, core goals, types of processes supported and underlying theory, types of task support and intended user group. They used this typology to analyse 11 existing tools, including the CASCADE-SEA system. Building on this work (Nieveen \& Gustafson, 1999), Table 1 presents the characterization of CASCADE-SEA and key questions to help identify characteristics of a new system that could synergistically support teachers in the processes of learning analytics, learning design and inquiry. Answers to these questions would help understand how to realize the above-mentioned design tenet: embedding the tool in meaningful experiences of teachers.

Table 1. CASCADE-SEA and questions about a new support system

\begin{tabular}{|c|c|c|}
\hline & CASCADE-SEA & Research to inform new integrated systems \\
\hline \multirow[b]{2}{*}{$\begin{array}{l}\text { Curriculum } \\
\text { level }\end{array}$} & Course and lesson & $\begin{array}{l}\text { For which courses are teachers most likely to seek deep } \\
\text { understanding through experience? }\end{array}$ \\
\hline & Secondary schools & $\begin{array}{l}\text { At which grade levels are teachers most naturally } \\
\text { inclined to consider how learning analytics can inform } \\
\text { design and frame inquiry? }\end{array}$ \\
\hline \multirow[b]{2}{*}{$\begin{array}{l}\text { Characteristics } \\
\text { of results }\end{array}$} & $\begin{array}{l}\text { Terminal results: Paper- } \\
\text { based teacher guides }\end{array}$ & $\begin{array}{l}\text { Terminal results: What kinds of educative materials do } \\
\text { teachers desire most and why? }\end{array}$ \\
\hline & $\begin{array}{l}\text { Interim results: resources } \\
\text { for analytics, design and } \\
\text { inquiry }\end{array}$ & $\begin{array}{l}\text { Interim results: What tools do teachers already have and } \\
\text { lack for analytics, design and inquiry? How do they use } \\
\text { them and with what results? }\end{array}$ \\
\hline $\begin{array}{l}\text { Purpose of the } \\
\text { tool }\end{array}$ & $\begin{array}{l}\text { Task performance } \\
\text { Better transfer } \\
\text { Organizational learning }\end{array}$ & $\begin{array}{l}\text { According to teachers, educational leaders and research } \\
\text { findings, what is the current state of teacher performance } \\
\text { of analytics, design and inquiry tasks and what influences } \\
\text { this? }\end{array}$ \\
\hline $\begin{array}{l}\text { Elements of } \\
\text { approach }\end{array}$ & $\begin{array}{l}\text { Rationale } \\
\text { Analysis } \\
\text { Design } \\
\text { Evaluation }\end{array}$ & $\begin{array}{l}\text { Bearing in mind the relationships described previously } \\
\text { (between: rationale/analysis } \approx \text { learning analytics; design } \\
\approx \text { learning design; and evaluation } \approx \text { teacher inquiry), do } \\
\text { teachers prioritise certain elements over others? If so, } \\
\text { why and with what results? }\end{array}$ \\
\hline $\begin{array}{l}\text { Types of } \\
\text { support }\end{array}$ & $\begin{array}{l}\text { Advice } \\
\text { Communication aids } \\
\text { Learning opportunities } \\
\text { Tools }\end{array}$ & $\begin{array}{l}\text { What forms of experiential learning do teachers value } \\
\text { most and are there implications for the kinds of support } \\
\text { they seek for analytics, design and inquiry? }\end{array}$ \\
\hline $\begin{array}{l}\text { Adaptability } \\
\text { of support }\end{array}$ & Inside tool & $\begin{array}{l}\text { What form and degree of customization do teachers use } \\
\text { with existing tools and why? What are the implications } \\
\text { of this for new tools? }\end{array}$ \\
\hline $\begin{array}{l}\text { Type of user } \\
\text { group }\end{array}$ & Facilitator teachers & $\begin{array}{l}\text { How are do regular teachers perceive the tasks involved } \\
\text { in analytics, design and inquiry and what motivates their } \\
\text { engagement (or lack thereof) in each? }\end{array}$ \\
\hline Scope of use & Various organizations & $\begin{array}{l}\text { Do networks of potential user groups already exist and if } \\
\text { so, what are they like? }\end{array}$ \\
\hline $\begin{array}{l}\text { Technology } \\
\text { skill required }\end{array}$ & Low & $\begin{array}{l}\text { What technology skills and hardware can teachers } \\
\text { realistically be expected to have and use? }\end{array}$ \\
\hline $\begin{array}{l}\text { Technology } \\
\text { use scenario }\end{array}$ & Offline mostly & $\begin{array}{l}\text { What accessibility features (online/offline; large/small } \\
\text { screen; with/without keyboard) will align best with } \\
\text { teacher opportunity and inclination to use an integrated } \\
\text { system? }\end{array}$ \\
\hline
\end{tabular}

Design guidelines

A new tool would likely combine a mobile app with a web-based social space for sharing and remixing designs. A new system would augment the powerful features of the original system with current insights about using analytics to support a design inquiry of learning, specifically: 
- Learning analytics: Learning analytics is typically positioned in the context of online learning environments. Mobile technology can enable teachers to collect data in face-to-face settings, and the system would incorporate such data, and provide the tools to analyse them. Based on the feedback from CASCADE-SEA users, it can be anticipated that teachers would prefer: support for working in groups (social structures of learning and teaching practices); efficient tools for collecting data, e.g. during regular classroom interactions (pedagogydriven collection and analysis of data); and explicit guidance on how to use the findings (use of data to inform teaching and learning).

- Learning design: The system would provide tools and representations for teachers to articulate their conjectures about the potential effects of their designs on student learning, and relate these conjectures to expected evidence that would emerge from data they collect. Findings from the CASCADE-SEA retrospective analysis further suggest that the following attributes would be highly valued: a database of existing designs (language and forms for sharing designs); continuing to make the processes of design transparent and flexible (design practices); and tools to do the work, such as checklists, design guidelines, and draft content (tools).

- Teacher inquiry: The system would support and encourage teachers to review the (analysed) data, reflect on their implications for their conjectures, and share their findings with peers. The blend of tailor-made and user-specific advise was deemed clear, concise and beneficial in CASCADE-SEA system, which means its basic structure could be retained for helping users undertake the key processes in inquiry (question formulation, methods selection, collection and analysis of data, and sharing/reflecting on the findings as well as overall process).

- Synergies: The system would offer just-in-time support (e.g. tips, tools, templates) to continuously refine a single, core rationale; this could help users to stay focused on but also gradually elaborate at core considerations, while also helping align all other aspects in internally consistent fashion. CASCADE-SEA users appreciated the connections between elements (e.g. dependencies between rationale and design) and wondered if they could be stronger. At the very least, newer technologies may be able to offer more seamless integration of functionalities.

\section{Closing considerations}

As stated earlier, the purpose of the present study was to articulate how teachers might be supported in the synergistic processes that are integral to educational design, and how new insights from each of the three fields can help us do this well. The design guidelines described above are based on the stance that learning analytics, learning design and teacher inquiry can be mutually supportive. Guided by the research questions in Table 1, further studies are needed to ascertain if and how integrated tools with characteristics like those above can contribute to the quality of teaching and learning, and the three respective fields. To design and test new software, an educational design research approach (McKenney \& Reeves, 2012) may be most useful as that genre of inquiry strives toward developing both practical solutions to problems of practice and theoretical understanding, simultaneously.

The recent drive towards "evidence-based education" and learning analytics promoted the use of data to assess the effectiveness of educational practices and resources. Critics of these trends argue that education is highly context-specific and practitioner-dependent. The same intervention, led by different teachers in different classrooms, will achieve radically divergent results. One possible way to overcome this challenge is by adopting a citizen science approach. Bonney et al, (2009) define citizen science as a research approach that enlists the public in gathering scientific information. Applying this idea to educational practice, we envisage large numbers of teachers engaged in collection, annotation, interpretation and analysis of data in their classrooms. These data can then be aggregated to form a scientifically valid body of evidence. The retrospective analysis of an existing robust tool provided here provides a modest but concrete considerations for supporting teachers in dynamic and challenging processes of learning analytics, learning design and teacher inquiry, which can be synergistically combined during educational design. 
As exciting as we find this vision, we must note the challenges that it poses. First and foremost, there is an issue of culture and resources: to engage teachers as data-informed citizen design scientists, they need to adopt the necessary mindset, acquire new practices, and be afforded the time and resources required and awarded for their efforts. The second challenge is methodological: aggregating and integrating the results of multiple unique situated studies is far from trivial. A classification system needs to be developed, along with standards of data and analysis interchange, in order to make this possible. Finally, ethical dimensions of massive practitioner research in real-life settings need to be carefully considered: How to we protect learners' rights in such a scenario? All three of these challenges define a research agenda and a blueprint for supporting technologies. We see this as a beacon for valuable future research. 


\section{References}

Avramides, K., Hunter, J., Oliver, M. \& Luckin, R. (in press). A method for teacher inquiry in crosscurricular projects: lessons from a case study. British Journal of Educational Technology

Anastopoulou, S.; Sharples, M.; Ainsworth, S.; Crook, C.; O'Malley, C. \& Wright, M. (2012), 'Creating Personal Meaning through Technology-Supported Science Inquiry Learning across Formal and Informal Settings', International Journal of Science Education 34 (2), 251-273

Bannan-Ritland, B. (2008) Teacher Design Research: an Emerging Paradigm for Teacher's Professional Development', Kelly, AE; Lesh, RA; Baek, JY Handbook of Design Research Methods in Education: Innovations in Science, Technology, Enginnering and Mathematics Learning and Teaching. New York: Routledge

Black, P., \& Wiliam, D. (1998). Assessment and classroom learning. Assessment in Education, 5(1), 7-72.

Bonney, R.; Cooper, C. B.; Dickinson, J.; Kelling, S.; Phillips, T.; Rosenberg, K. V. \& Shirk, J. (2009) Citizen science: a developing tool for expanding science knowledge and scientific literacy', BioScience 59(11):977-984

Davies, P. (1999). What is evidence-based education?, British journal of educational studies 47(2):108-121.

Emin-Martínez, V.; Hansen, C.; Rodríguez-Triana, M. J.; Wasson, B.; Mor, Y.; Dascalu, M.; Ferguson, R. \& Pernin, J.-P. (2014), 'Towards teacher-led design inquiry of learning', eLearning Papers (36)

Ferguson, Rebecca (2012). Learning analytics: drivers, developments and challenges. International Journal of Technology Enhanced Learning, 4(5/6) pp. 304-317. http://oro.open.ac.uk/36374/

Kali, Y.; Goodyear, P. \& Markauskaite, L. (2011), Researching design practices and design cognition: contexts, experiences and pedagogical knowledge-in-pieces, Learning, Media and Technology 36 (2) , 129-149

Korthagen, F., Kessels, J., Koster, B., Lagerwerf, B., Wubbels, T. (2001). Linking practice and theory: The pedagogy of realistic teacher education. Mahwah, NJ: Lawrence Erlbaum.

Makri, K., Papanikolaou, K., Tsakiri, A. \& Karkanis, S. (2014). Blending the Community of Inquiry Framework with Learning by Design: Towards a Synthesis for Blended Learning in Teacher Training. The Electronic Journal of e-Learning, 12, 183-078.

McKenney, Nieveen \& van den Akker. (2002) "Computer support for curriculum developers: CASCADE." Educational technology research and development 50.4 (2002): 25-35.

McKenney, S. \& Reeves, T. (2012) Conducting Educational Design Research, Routledge , London

McKenney, S. \& van den Akker, J. (2005). Computer-based support for curriculum designers: A case of developmental research. Educational Technology Research and Development 53(2) 41-66.

McKenney, S. (2005). Technology for curriculum and teacher development: Software to help educators learn while designing teacher guides. Journal of Research on Technology in Education, 38(2) 167-190.

McKenney, S. (2008). Shaping Computer-based support for curriculum developers. Computers \& Education 50(1) 248-261.

McKenney, S., Nieveen, N. \& Strijker, A. (2008). Information Technology Tools for Curriculum Development. In J. Voogt \& G. Knezek (Eds.) International Handbook of Information Technology in Education (pp. 195-210). London: Springer.

McKenney, S., \& Reeves, T. (2013). Electronic performance support for curriculum materials developers: A design research project in Sub-Saharan Africa. In T. Plomp, \& N. Nieveen (Eds.), Educational design research - Part B: Illustrative cases (pp. 533-555). Enschede, the Netherlands: SLO.

Mor, Y. \& Craft, B. (2012), 'Learning Design: mapping the landscape', Research in Learning Technology 20

Mor, Y.; Hernández-Leo, D. \& Craft, B (2013), The Art and Science of Learning Design (Editorial), Research in Learning Technology, 21

Pareja- Roblin, N., Ormel, B., McKenney, S., Voogt, J. \& Pieters, J. (in press). Linking research and practice through teacher communities: A place where formal and practical knowledge meet? European Journal of Teacher Education. 
McKenney, S., Nieveen, N. \& Strijker, A. (2008). Information Technology Tools for Curriculum Development. In J. Voogt \& G. Knezek (Eds.) International Handbook of Information Technology in Education (pp. 195-210). London: Springer.

Nieveen, N. (1997). Computer-based support for curriculum developers: A study on the potential of computer support in the domain of formative curriculum evaluation. Doctoral dissertation, University of Twente, Enschede.

Nieveen, N., \& Gustafson, K. (1999). Characteristics of computer-based tools for education and training development: An introduction. In Design approaches and tools in education and training (pp. 155-174). Springer Netherlands.

Persico, D. \& Pozzi, F. (in press). Informing learning design with learning analytics to improve teacher inquiry. British Journal of Educational Technology

Unwin, T. (2005), 'Towards a framework for the use of ICT in teacher training in Africa', Open Learning: The Journal of Open, Distance and e-Learning 20 (2), 113-129.

Voogt, J.; Westbroek, H.; Handelzalts, A.; Walraven, A.; McKenney, S.; Pieters, J. \& de Vries, B. (2011), 'Teacher learning in collaborative curriculum design', Teaching and Teacher Education 27 (8), 1235 - 124

Sagy, O. \& Kali, Y. (2014). Teachers as Design-Researchers of Technology-Enhanced Learning. Proceedings of the 9th Chais Conference for the Study of Innovation and Learning Technologies: Learning in the Technological Era

Schön, D. A. (1992), 'The theory of inquiry: Dewey's legacy to education', Curriculum inquiry 22 (2), 119-139.

Slavin, R. E. (2002). Evidence-based education policies: Transforming educational practice and research. Educational Researcher, 31, 15-21 


\section{Figures}

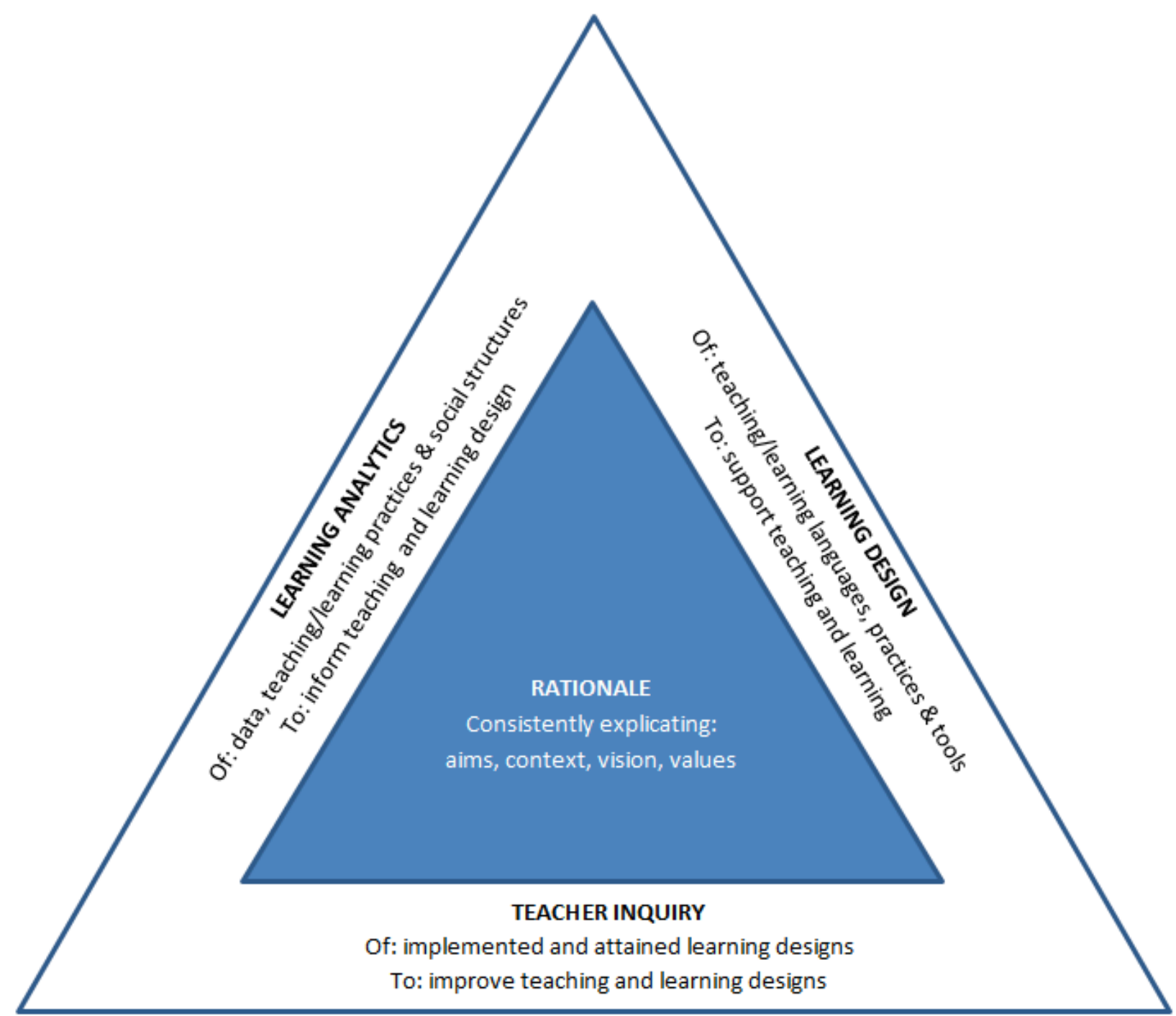

Figure 1. Learning analytics, learning design and teacher inquiry synergistically support core rationale 


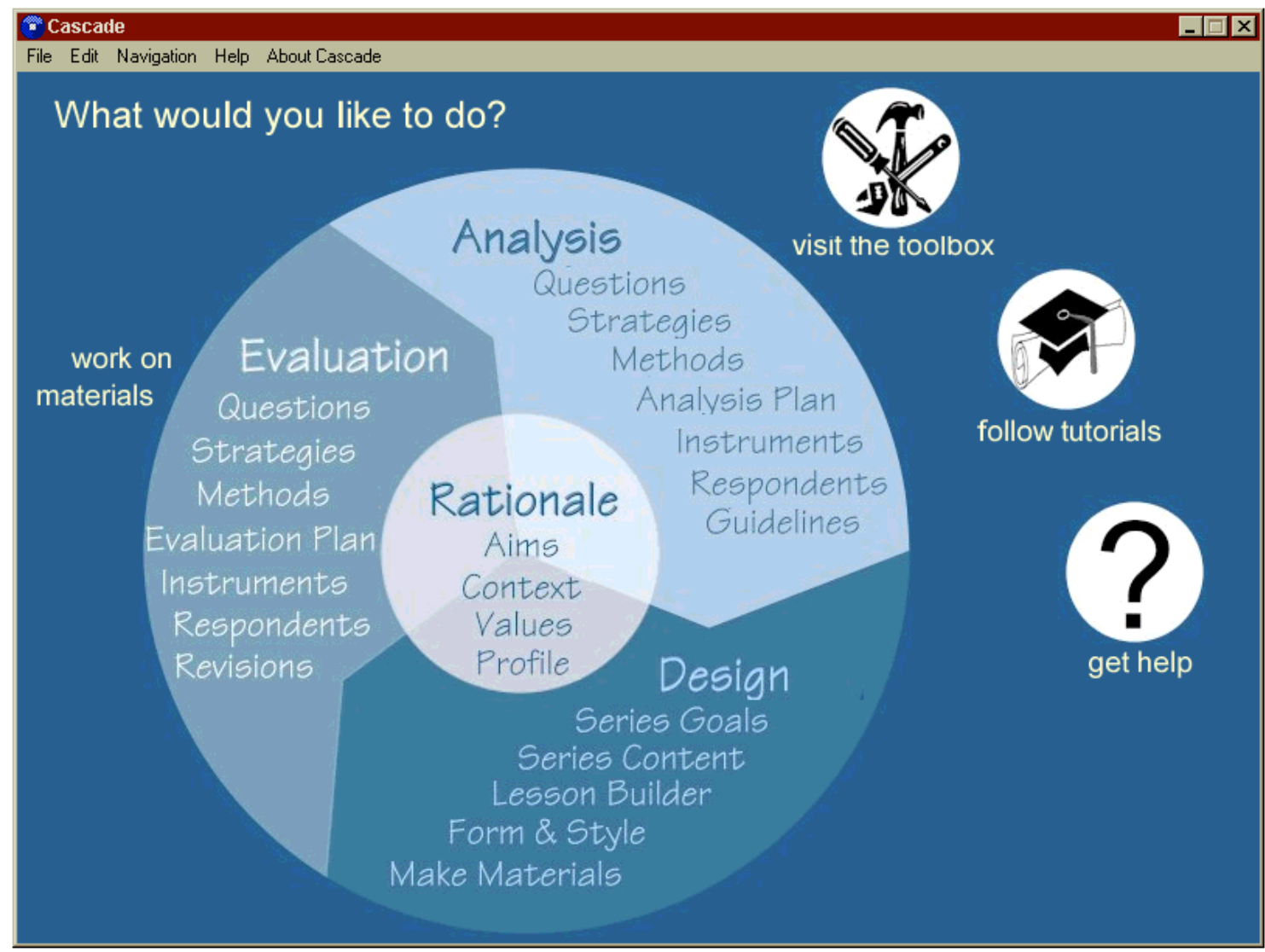

Figure 2. CASCADE-SEA (main menu screenshot) 

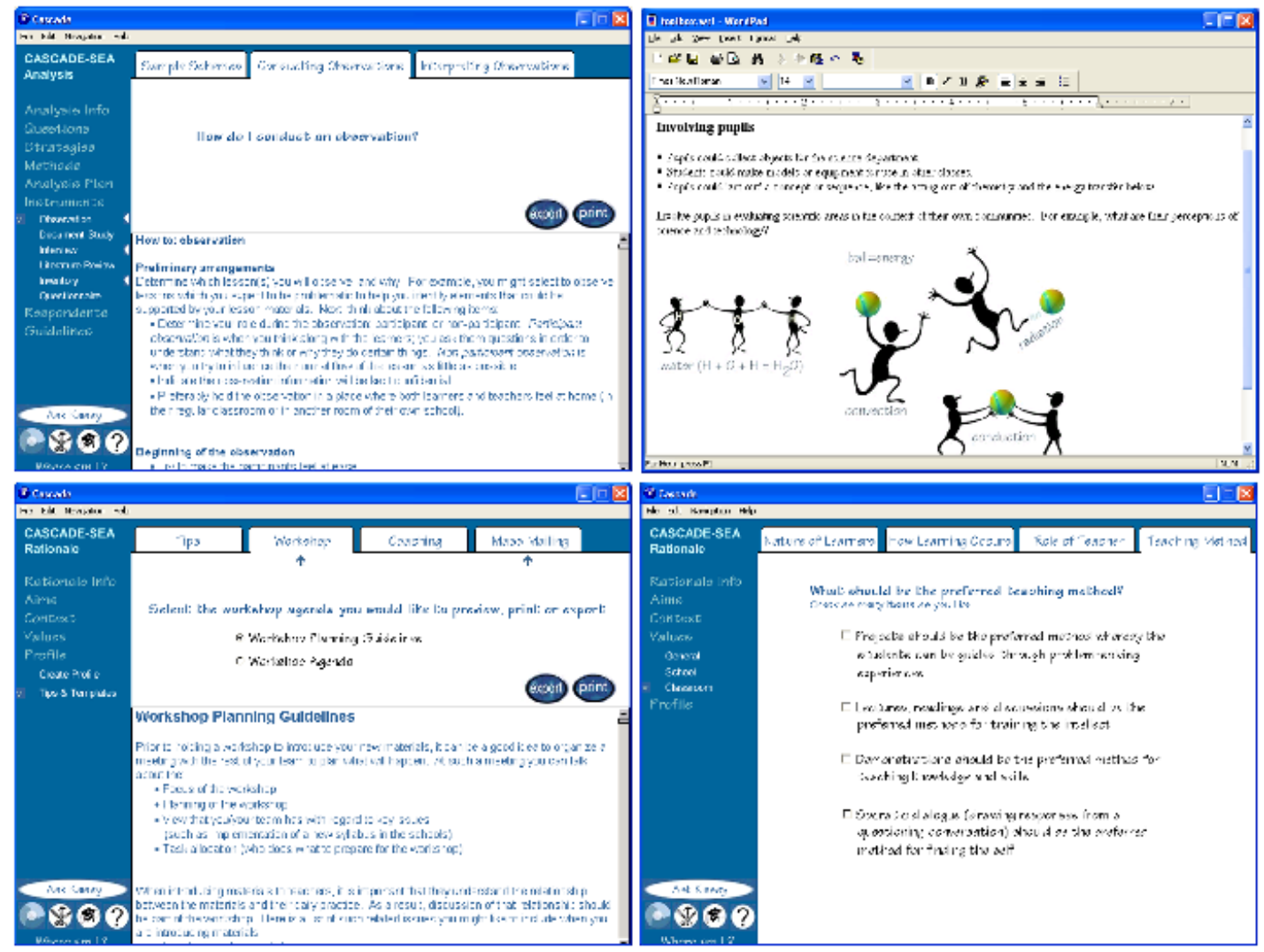

Figure 3. Samples of support within CASCADE-SEA (clockwise: advice on how to conduct an observation; tool in form of draft lesson plan; learning opportunity about planning workshops; communication aid in questions for designers to discuss) 